\title{
MENCARI FAKTOR-FAKTOR PSIKIS PENYEBAB TERJADINYA DYSCALCULIA
}

\author{
Sumadji \\ Pendidikan Matematika, Universitas Kanjuruhan Malang \\ idjamus@yahoo.com
}

\begin{abstract}
Abstrak: Faktor yang mempengaruhi keberhasilan belajar jumlahnya banyak. Faktor IQ dan faktor bersifat fisik dan eksternal sudah banyak diteliti oleh berbagai pihak. Penelitian ini bertujuan mencari faktor-faktor psikis yang menjadi penyebab terjadinya dyscalculia (kesulitan belajar matematika) di kalangan mahasiswa. Penelitian ini dilakukan di Universitas Kanjuruhan Malang pada program studi pendidikan matematika. Subyek penelitian ini adalah mahasiswa yang menempuh matakuliah KPB pada semester genap tahun 2016/2017 sebanyak 36 orang. Kuliah tersebut diampu sendiri oleh peneliti. Instrumen UTS dan UAS telah valid dan reliabel diambil dari dokumen bank soal dengan melakukan sedikit modifikasi. Angket yang digunakan terdiri atas 11 butir mewakili faktor-faktor psikis selain IQ. Satu faktor diantaranya dikembangkan menjadi tiga butir. Validitas dan reliabilitas angketdianalisis berbantuan program SPSS 16.0. Adanya gangguan dyscalculia dapat diketahui dari kinerja mahasiswa pada lembar UTS dan UAS. Taraf kesulitan dibedakan atas tiga kategori yaitu kesulitan ringan, sedang, dan berat. Setelah diketahui adanya gangguan dyscalculia, maka untuk mengetahui faktor psikis penyebabnya digunakan angket. Untuk mendalami masalah penyebab, penulis melakukan wawancara dengan 6 butir pertanyaan terbuka terhadap 10 responden dipilih secara proporsional dari mahasiswa terindikasi dyscalculia bertaraf sedang dan berat. Hasil dari penelitian adalah semua mahasiswa terindikasi mengalami dyscalculia dengan rincian taraf ringan $3 \%$, taraf sedang $28 \%$ dan berat $69 \%$. Mahasiswa yang merasa 'ingatan/kemampuannya kurang' dalam memahami KPB berjumlah 92,6\%, 'kurang/sulit fokus' terhadap materi kuliah $63 \%$ dan mahasiswa yang cukup percaya diri tetapi "cukup malu" dan "agak cemas" ketika kuliah, tes atau presentasi sebanyak 59,3\%.
\end{abstract}

Kata Kunci: faktor-faktor psikis; dyscalculia.

\section{Pendahuluan}

Belajar perlu potensi, semangat, minat dan lain-lain bagian dari faktorfaktor psikis yang mempengaruhi keberhasilannya. Belajar perlu dilakukan secara intensif memusatkan daya dan pikiran untuk memahami tema-tema kompleks dan abstrak. Berhubungan dengan hal itu, Sardiman (2006:84) menyatakan bahwa dalam belajar perlu intensitas atau semangat yang tinggi.

Setiap saat mahasiswa harus memecahkan masalah, diminta unjuk kemampuan di depan kelas, presentasi, diskusi atau menyelesaikan tugas yang semua menjadi beban. Tumpukan bebanbeban tersebut kemungkinan besar dapat menimbulkan kecemasan yang akhirnya berpengaruh terhadap kekuatan belajar mereka. Diduga $20 \%$ populasi dunia menderita kecemasan dan lebih dari $47 \%$ remaja sering merasa cemas (Haryadi, 2007). Dalam batas yang wajar, rasa cemas memiliki dorongan belajar agar tidak tertinggal. Orang yang tidak cemas terkadang dapat belajar tanpa beban sehingga menghasilkan hasil maksimal.

Kondisi belajar di mana penelitian ini dilakukan, ditingkatkan kualitasnya misalnya fasilitas dan ruangan. Iklim dan proses perkuliahan juga telah memenuhi standar penjaminan mutu. Namun pada setiap semester hasil belajar pada matakuliah yang penulis ampu tidak memuaskan. Berdasarkan pengalaman, jumlah mahasiswa yang dapat berhasil tidak lebih dari 20\% saja. Ditambah lagi hasil penelitian sebelumnya menunjukkan 
bahwa motivasi belajar mahasiswa pada tingkatan "sedang" dan cara belajarnya "kurang" (Sumadji, 2010).

Hasil penelitian Caryono, dkk. (2012) menyatakan bahwa faktor psikologis merupakan penyebab terbesar terjadinya dyscalculia. Cara belajar yang kurang baik dan tak teratur merupakan faktor terbesar. Penelitian Sholikah dan Slamet (2011) menunjukkan bahwa mahasiswa tidak dapat berkonsentrasi dan tidak bisa memperkirakan waktu.

Analisis kesalahan penyelesaian soal persamaan differensial menunjukkan bahwa mahasiswa tak menguasai konsepkonsep prasyarat seperti turunan dan integral lebih dari 40\% (Sufiyah, 2002). Berhubungan dengan hal-hal tersebut, Syah (2010:166) mengatakan bahwa itu merupakan indikasi terjadi ketidakmampuan belajar matematika atau dyscalculia.

Hasil-hasil penelitian di atas penulis rasa masih kurang mendalam dan kurang mendasar. Karena itu masih perlu diketahui lebih jauh penyebabnya agar kesulitan dapat diminimalisasi. Berdasar uraian tersebut yang menjadi masalahnya adalah faktor-faktor psikis apa yang menjadi penyebab terjadinya dyscalculia?

\section{Faktor-Faktor Psikis}

Faktor psikis adalah keadaan kejiwaan seseorang yang dapat mempengaruhi proses dan hasil belajar individu. Faktor-faktor tersebut adalah 1) kecerdasan, berfungsi sebagai prediktor yang efektif terhadap performa individu baik dalam pendidikan atau di lingkungan kerja, 2) motivasi yaitu psikologis seseorang yang mendorong melakukan kegiatan tertentu guna menggapai tujuannya, 3) ingatan, adalah kecakapan menerima, menyimpan dan mereproduksi kesan, 4) minat adalah kecenderungan tetap dalam memperhatikan suatu hal yang diikuti rasa senang, 5) sikap adalah kecenderungan merespons sesuatu yang membawa diri sesuai dengan penilaian, 6) bakat adalah kecakapan khusus dalam melakukan tugas tanpa tergantung upaya pendidikan dan latihan; meliputi bakat verbal, numerikal, skolastik, abstrak, mekanik, spasial, klerikal, dan bahasa, 7) rasa percaya diri yaitu sikap tidak perlu membandingkan dengan orang lain, berpikir secara original dalam pemecahan masalah, bertanggung jawab atas yang dilakukan, 8) kebiasaan belajar yaitu segenap perilaku teratur dan berulang dalam kegiatan belajar; dan 9) cita-cita; wujud eksplorasi dan emansipasi diri.

\section{Kesulitan Mengerjakan Matematika}

Matematika memiliki ciri-ciri: a) obyeknya abstrak yaitu fakta, konsep, operasi dan prinsip, b) bertumpu pada kesepakatan, misalnya axioma, konsep dan primitif, c) pola pikir deduktif, d) memiliki simbol yang kosong dari arti, e) terikat oleh semesta pembicaraan, dan f) konsisten dalam sistemnya.

Menurut Mason, dkk.(2010) proses berfikir matematika memiliki tiga fase yaitu fase masuk (entry phase), fase menyelesaikan (attack phase), dan fase review (review phase). Pada fase 'masuk' antara lain dilakukan pengenalan dan definisi masalah, mengklasifikasi, mengenali masalah, simbol, atau notasi.

$$
\text { Pada fase 'menyelesaikan' }
$$

dilakukan semua aktifitas matematika yang diperlukan untuk menyelesaikan masalah. Pengetahuan tentang teknik, prinsip, atau konsep matematika menjadi syarat utama dalam fase ini. Kemampuan intelektual, kreatifitas, ingatan, dan ketrampilan akan mempengaruhi keberhasilan dalam fase ini (Davidson dan Sternberg, 2003).

Fase ketiga fase review, berguna dalam refleksi atas fase-fase sebelumnya. Fase ini membantu memeriksa apakah proses berfikir matematika benar dan masalah yang telah diselesaikan dapat diletakkan dalam konteks yang lebih luas.

Proses berfikir dalam matematika memerlukan daya lebih besar daripada 
proses berfikir bidang-bidang seperti ilmu sosial. Dalam matematika tidak cukup hanya menghafal sebagai usaha menguasai fakta atau kesepakatan. Adanya materi yang abstrak seperti di atas dan kosong dari arti akan mendorong seseorang melepaskan diri dari kenyataan dan dituntut melakukannya secara abstrak (dalam kognitif) dan logis dalam pengambilan kesimpulannya. Pada tahap ini, seseorang harus membandingkan konsep, menginterpretasi fenomena atau abstraksi tertentu, dan dapat simpulan tentang ide pokok suatu pembahasan.

Untuk beberapa bagian materi matematika, masih memerlukan proses berikutnya yaitu melakukan analisis, evaluasi dan sintesis. Sedangkan tahap komprehensif dan berfikir kritis jarang diperlukan dalam matapelajaran lainnya. Berfikir matematika akan berkembang dengan baik jika proses berfikir matematika dilakukan melalui tiga fase secara berkesinambungan. Inilah yang mengakibatkan berfikir matematika perlu daya dan tingkatan berfikir lebih tinggi dari ilmu pengetahuan lainnya.

Perilaku yang menunjukkan terjadinya kesulitan adalah: 1) hasil belajar yang rendah; 2) hasil yang dicapai tidak seimbang dengan usaha; 3 ) bekerja lambat; 4) bersikap kurang wajar, seperti menentang, berpura-pura, berdusta; 5) bertingkah berbeda seperti terlambat, mengasingkan diri, tidak kooperatif ; 6) emosikurang wajar seperti pemurung, mudah tersinggung, pemarah, performa kurang gembira (Hallen, 2005).

Indikasi lain terjadinya kesulitan belajar pada individu adalah munculnya rasa cemas. Gejala ini termasuk dalam gejala nomor 6 di atas. Dalam belajar matematika dibutuhkan konsentrasi karena matematika adalah bidang ilmu yang berkenaan dengan ide-ide, strukturstruktur dan hubungan-hubungan yang diatur secara logis. Matematika punya kesulitan yang tinggi sehingga memicu meningkatnya kecemasan.
Berhubungan dengan hal di atas, Freud mengatakan bahwa apabila tidak dapat mengendalikan kecemasan melalui cara-cara yang rasional, maka ego akan mengandalkan cara-cara yang tidak realistis (Fudyartanta, 2012). Namun bila siswa telah berhasil mengantisipasi dan mengatasi gejala-gejala kecemasan, maka perasaan ini akan menjadi sumber motivasi seperti yang diutarakan oleh Corey (2010) bahwa kecemasan adalah suatu keadaan tegang yang memotivasi kita untuk berbuat sesuatu. Kecemasan dapat menjadi tenaga motivasional kuat dalam belajar dan membangun semangat untuk lebih rajin belajar.

\section{Keberhasilan Belajar Matematika}

Sebagaimana yang diungkapkan oleh Mulyasa (2010), bahwa tugas guru tidak hanya menyampaikan informasi kepada peserta didik, tetapi harus menjadi fasilitator yang memberikan kemudahan belajar.Proses pembelajaran yang akan disiapkan oleh guru harus memperhatikan teori-teori dasar dan implikasinya dalam pembelajaran.

Dalam kenyataan pembelajaran matematika di sekolah banyak siswa yang mengalami kesulitan menyelesaikan soalsoal. Menurut Soleh (1999:34) yang matematika memiliki objek abstrak, konsep dan prinsipnya berjenjang, dan prosedur kerjanya banyak memanipulasi bentuk-bentuk ternyata menimbulkan kesulitan dalam belajar matematika.

Kesulitan belajar menurut Soleh (1999) mencakup lima hal yaitu: 1) Learning disorder, kekacauan belajar, 2) Learning disfunction, gejala belajar yang dilakukan tidak berfungsi dengan baik, 3) Under achiever, tingkat potensi intelektual di atas normal, tetapi memiliki prestasi belajar rendah, 4) Slow learner, lambat belajar sehingga butuh waktu lebih lamadari siswa lain dalam potensi intelektual sama, 5) Learning disabilities, siswa tidak menghindari 
belajar sehingga hasilnya di bawah potensi intelektualnya.

\section{Metode Penelitian}

Penelitian ini terdiri atas tiga tahap. Tahap pemberian tes dan penyebaran angket diselesaikan dengan metode penelitian deskriptif kuantitatif. Tahap terakhir dengan metode kualitatif penulis mewawancarai mahasiswa terindikasi dyscalculia untuk mengetahui lebih mendalam adanya faktor-faktor psikis.

Subyek dalam penelitian ini adalah mahasiswa kelas 2015C yang menempuh kuliah KPB. Perkuliahan diampu oleh penulis dalam 14 kali pertemuan (@150 menit) dan 2 kali tes (@90 menit). Proses pembalajarannya adalah 50 menit pertama mahasiswa mempresentasikan makalah yang disusun oleh kelompoknya dilanjutkan diskusi klasikal. Pada 50 menit berikutnya perkuliahan diambil alih dosen untuk membenahi kesalahan dan kekurangan yang terjadi sebelumnya. Selama waktu tersisa mahasiswa melatih ketrampilan memecahkan masalah dibimbing dosen.

Tahap pertama penelitian ingin mengetahui apakah dalam kuliah KPB adamahasiswa mengalami dyscalculia. Untuk mengetahuinya akan dilaksanakan Ujian Tengah Semester (UTS) dan Ujian Akhir Semester (UAS). Mahasiswa yang mendapatkan nilai $\mathrm{B}+$ atau kurang tentu mengalami kesulitan. Kesulitan mereka yang mendapat nilai A- dapat diabaikan.

Penelitian tahap dua menelaah lembar kerja mahasiswa yang mengalami dyscalculia. Pada bagian tersebut penulis memaparkan kesalahan yang ada sambil membandingkan dengan kunci jawaban. Penulis tidak membahas kesalahankesalahan tersebut berdasar teori tertentu.

Penelitian tahap tiga memberikan angket terhadap mahasiswa terindikasi dyscalculiauntuk mengetahui faktor- faktor psikis penyebabnya. Angket terdiri atas 11 butir sesuai dengan banyaknya faktor psikis kecuali faktor IQ. Untuk butir 'rasa percaya diri' dikembangkan menjadi 3 butir yaitu (1) rasa percaya diri, (2) rasa malu, dan (3) kecemasan. Hasil angket dianalisis dengan persentasi kemudian disimpulkan secara verbal.

Untuk mendalami faktor-faktor psikis penyebab terjadinya dyscalculia, pada tahap terakhir peneliti melakukan wawancara kepada responden terpilih. Wawancara berpedoman pada lembar berisi 6 pertanyaan terbuka dan akan terus berkembang jika ditemukan hal-hal bermanfaat yang mengungkap masalah. Hasil wawancara akan disimpulkan sebagaimana dikatakan oleh Soegiyono (2007:244) bahwa analisis data kualitatif adalah proses mencari dan menyusun secara sistematis diorganisasi ke dalam kategori, menjabarkan ke dalam unit-unit, melakukan sintesa, menyusun ke dalam pola, memilih yang penting dan membuat kesimpulan yang mudah dipahami.

\section{Hasil dan Pembahasan}

Dari rerata hasil UTS dan UAS diketahui bahwa distribusi banyaknya mahasiswa yang mengalami dyscalculia seperti tertulis di Tabel 1. Tabel 1 mengatakan bahwa semua mahasiswa mengalami dyscalculia. Berdasarkan lembar kerja mahasiswa, kesalahan yang mereka perbuat merata meliputi kesalahan konsep, kurang mengenal fakta, kurang memahami rumus, kurang terampil hingga kurang disiplin. Berikut ini adalah salah satu hasil kerja mahasiswa yang mengalami kesulitan berat SN Skor 28.

\section{Soal nomor 1}

Tuliskan dengan notasi integral yang menyatakan luas daerah dalam kurva $r=4+4 \cos \theta$ (tidak perlu dihitung). Mahasiswa menuliskan jawab sbb.:

$$
r=4+4 \cos \theta=4(1+\cos \theta)
$$




$$
\begin{gathered}
\leftrightarrow 4+4 \cos \theta=0 \\
\leftrightarrow 4 \cos \theta=-4 \\
\leftrightarrow \cos \theta=\frac{-4}{4} \\
\leftrightarrow \cos \theta=-1 \\
\leftrightarrow \theta=180 \leftrightarrow \theta=\pi \\
L=4 \int_{0}^{\pi} \int_{r=0}^{r} r d r d \theta .
\end{gathered}
$$

Pekerjaan di atas tidak bermanfaat dalam penentuan batas integral. Batas dapat ditentukan jika mampu menggambarkan kurva terkait. Kunci jawabnya sbb.:

$$
\begin{aligned}
& \text { Luas } L=2 \int_{\theta=0}^{\theta=\pi} \int_{r=0}^{r=4+4 \cos \theta} r d r d \theta \text { atau } \\
& L=\int_{\theta=0}^{\theta=2 \pi} \int_{r=0}^{r=4+4 \cos \theta} r d r d \theta
\end{aligned}
$$

\section{Soal nomor 2}

Tuliskan dengan notasi integral, luas permukaan silinder $x^{2}+z^{2}=1$ di oktan pertama dibatasi oleh bidang $x+y=2$ (jangan dihitung hasilnya).

Mahasiswa tidak menulis jawab apapun.

\section{Soal nomor 3}

Hitunglah $\int_{0}^{\frac{1}{2} \pi} \int_{0}^{\pi} \int_{0}^{r} \rho^{2} \sin \phi d \rho d \theta d \phi$

Mahasiswa ini menjawab seperti:

$=\int_{0}^{\frac{1}{2} \pi} \int_{0}^{\pi}\left[\frac{1}{3} \rho^{3}\right]_{0}^{r} \sin \phi d \rho d \theta$

$=\frac{1}{3} \int_{0}^{\frac{1}{2} \pi} \int_{0}^{\pi} r^{3} \sin \phi d \rho d \theta=\ldots$

dan seterusnya dalam keadaan salah menghasilkan $\frac{1}{3} \pi r^{3}$. Kesalahannya $d \rho$ seharusnya tidak muncul karena sudah dioperasikan, $d \rho \quad$ seharusnya $d \theta$, serta $d \theta$ seharusnya $d \phi$. Kunci jawabnya sbb.:

$$
\begin{gathered}
\int_{0}^{\pi} \int_{0}^{2 \pi} \frac{1}{3} \rho^{3} \sin \phi d \theta d \phi \\
=\frac{1}{3} \int_{0}^{\pi} \int_{0}^{2 \pi} r^{3} \sin \phi d \theta d \phi \\
=\frac{1}{3} \int_{0}^{\pi} \theta r^{3} \sin \phi d \phi=\frac{2}{3} \pi r^{3} \int_{0}^{\pi} \sin \phi d \phi \\
=-\frac{2}{3} \pi r^{3}[\cos \phi]_{0}^{\pi}=\frac{4}{3} \pi r^{3} .
\end{gathered}
$$

\section{Soal nomor 4}

Hitunglah integral $\int_{1}^{2} \int_{1}^{2 x} \int_{0}^{\sqrt{\frac{y}{x}}} 4 x y z d z d y d x$.

Mahasiswa mengerjakan seperti ini.

$$
\int_{1}^{2} \int_{1}^{2 x} \int_{0}^{\sqrt{\frac{y}{x}}} 4 x y z d x d y d z=\int_{1}^{2} \int_{1}^{2 x}[4 x y]_{0}^{\sqrt{\frac{y}{x}}} d x d y
$$

Kesalahannya adalah merubah/membalik susunan integral. Pekerjaannya berlanjut salah tetapi tidak tuntas diselesaikan.

Sedangkan kunci jawabnya adalah:

$$
\begin{aligned}
& \int_{1}^{2} \int_{1}^{2 x} 2 x y z^{2} d y d x=\int_{1}^{2} \int_{1}^{2 x} 2 y^{2} d y d x \\
& =\frac{2}{3} \int_{1}^{2} y^{3} d x=\frac{2}{3} \int_{1}^{2}\left[8 x^{3}-1\right] d x
\end{aligned}
$$

\section{Soal nomor 5}

Hitunglah luas permukaan/bidang silinder $x^{2}+y^{2}=9$ di oktan pertama dari $z=0$ sampai $y+z=5$.

Mahasiswa mengerjakan seperti

$$
\begin{aligned}
& \text { ini. } L=\iint \frac{\sqrt{4 x^{2}+4 x^{2}+0}}{2 x} d x y d z \\
& =\iint \frac{\sqrt{4 x^{2}+4 x^{2}+0}}{2 x} d y d z \\
& =\frac{2.3}{2} \iint \frac{1}{x} d y d z=3 \int_{y=-3}^{y=3} \int_{z=0}^{z=5-y} \frac{1}{\sqrt{y-y^{2}}} d z d y
\end{aligned}
$$


$=3 \int \frac{[z]_{0}^{z=5-y}}{\sqrt{y-y^{2}}} d y=3 \int \frac{5-y}{\sqrt{y-y^{2}}} d y$.

Substitusi $y=3 \sin t, d y=3 \cos t d t$, maka (selanjutnya benar seperti kunci jawab).

Disini mahasiswa awalnya kacau dengan menulis $4 \mathrm{x}^{2}$ lagi dan $d x y$. Mahasiswa ini terindikasi menyontoh kawannya karena pekerjaan yang salah ini dilakukan oleh beberapa orang mahasiswa sama persis. Perhatikan bahwa penyebut $y$ di bawah tanda akar seharusnya 9.Kunci jawabnya adalah seperti ini.

$$
\begin{aligned}
& L=\int_{-3}^{3} \int_{z=0}^{z=5-y} \frac{\sqrt{4 x^{2}+0+4 z^{2}}}{2 x} d z d y= \\
& \int_{-3}^{3} \int_{z=0}^{z=5-y} \frac{3}{\sqrt{9-y^{2}}} d z d y .
\end{aligned}
$$

Misalkan $\quad y=3 \sin t, d y=3 \cos t d t$,

maka $L=\int_{-3}^{3} \int_{z=0}^{z=5-y} \frac{3}{\sqrt{9-y^{2}}} d z d y=$

$\int_{-3}^{3} \frac{3[z]_{0}^{5-y}}{\sqrt{9-y^{2}}} d y$

$$
\begin{gathered}
=3 \int \frac{5-y}{\sqrt{9-y^{2}}} d y= \\
3 \int \frac{5-3 \sin t}{3 \cos t} \cdot 3 \cos t d t=\int(15-9 \sin t) d t \\
=[15 t+9 \cos t]_{0}^{\frac{\pi}{2}}
\end{gathered}
$$

Dari hasil UTS dan UAS dapat diketahui adanya kesulitan belajar yang menimpa semua mahasiswa. Hasilnya dirangkum dalam tabel 1 berikut.

Tabel 1. Distribusi Kesulitan Belajar

\begin{tabular}{lccl}
\hline Taraf Kesulitan & Skor & Frek. & \% \\
\hline Tanpa Kesulitan & $91-100$ & 0 & 0 \\
Kesulitan Ringan & $76-90$ & 1 & 3 \\
Kesulitan Sedang & $46-75$ & 10 & 28 \\
Kesulitan Berat & $0-45$ & 25 & 69 \\
\hline
\end{tabular}

Setelah mengetahui bahwa pada perkuliahan semua mahasiswa terindikasi dyscalculia, maka penulis memberikan angket. Pilihan jawab yang dipilih oleh responden dengan taraf (grade) 'sangat' atau 'cukup' dan bermakna 'positif' bukan merupakan faktor penyebab terjadinya dyscalculia. Pilihan jawab yang dipilih mahasiswa bermakna 'negatif' dan bertaraf 'kurang' atau 'tidak' merupakan faktor psikis penyebab terjadinya dyscalculia.

Faktor-faktor psikis penyebab terjadinya dyscalculia adalah faktorfaktor yang memiliki grade 3 terdiri atas empat butir atau grade 4 (tetapi tidak adayang memilih). Faktor-faktor tersebut adalah: 1) ingatan/kemampuan menerima materi, 2) konsentrasi belajar, 3) rasa cukup percaya diri diikuti rasa 'cukup malu', dan 4) rasa cukup percaya diri diikuti rasa 'agak cemas' ketika tes, presentasi atau kuliah.

Hasil seperti tersebut di atas jarang terungkap oleh peneliti lain. Umumnya hanya digolongkan berdasar jenis kesulitannya. Oleh karena itu, upaya perbaikannya harus terkait dengan mengantisipasi empat hal penting yaitu ingatan/kemampuan, konsentrasi belajar, rasa cemas dan rasa malu.

Untuk mendalami temuan di atas, penulis melanjutkan dengan wawancara untuk mengetahui penyebab terjadinya dyscalculia. Wawancara dilakukan terhadap sepuluh responden dipilih secara proporsional dari mahasiswa mengalami dyscalculia taraf sedang dan berat. Rangkuman hasil wawancara disajikan sebagai berikut.

Tabel 2. Hasil Wawancara

\begin{tabular}{ll}
\hline $\begin{array}{c}\text { Butir } 5 \text { kenapa anda } \\
\text { mengalami kesulitan? }\end{array}$ & $\begin{array}{c}\text { Butir 6 apa saran } \\
\text { anda kepada } \\
\text { dosen? }\end{array}$ \\
\hline $\begin{array}{l}\text { materi sulit seperti } \\
\text { turunan parsial }\end{array}$ & $\begin{array}{l}\text { diajar oleh dosen } \\
\text { saja seluruhnya }\end{array}$ \\
\hline
\end{tabular}




\begin{tabular}{|c|c|}
\hline $\begin{array}{l}\text { banyak materi sulit, } \\
\text { presentasi kurang jelas }\end{array}$ & $\begin{array}{l}\text { presentasi harus } \\
\text { lebih serius }\end{array}$ \\
\hline $\begin{array}{l}\text { harga mutlak, turunan } \\
\text { parsial sulit }\end{array}$ & $\begin{array}{l}\text { perbaiki presentasi } \\
\text { kelompok }\end{array}$ \\
\hline $\begin{array}{l}\text { merekalemah di bagian } \\
\text { turunan dan integral }\end{array}$ & $\begin{array}{l}\text { tak perlu presentasi } \\
\text { kelompok }\end{array}$ \\
\hline $\begin{array}{l}\text { banyak materi sulit } \\
\text { untuk dihafal }\end{array}$ & $\begin{array}{l}\text { dibuat buku wajib } \\
\text { dan diajar dosen }\end{array}$ \\
\hline $\begin{array}{l}\text { mudah lupa, banyak } \\
\text { materi sulit dihafalkan }\end{array}$ & - \\
\hline $\begin{array}{l}\text { materi sulit dan presentasi } \\
\text { kurang membantu }\end{array}$ & $\begin{array}{l}\text { usahakan ada buku } \\
\text { pegangan wajib }\end{array}$ \\
\hline banyak materi sulit & tambah contoh real \\
\hline $\begin{array}{l}\text { turunan dan integral } \\
\text { sulit, presentasi sulit } \\
\text { diikuti }\end{array}$ & $\begin{array}{l}\text { tak ada presentasi, } \\
\text { dia-jar dosen } \\
\text { dengan buku }\end{array}$ \\
\hline $\begin{array}{l}\text { semua materi sulit } \\
\text { dihafal }\end{array}$ & diajar dosen saja \\
\hline
\end{tabular}

Jawaban terhadap butir 1, 2 dan 3 tidak ditampilkan. Seluruh responden menjawab sama atas pertanyaan mengenai kepemilikan buku cetak, kepemilikan buku catatan dan pernah belajar keras secara berkelompok. Jawaban mereka adalah"tidak", "punya" dan "pernah".

Untuk pertanyaan 4 (apa yang anda lakukan jika mengalami kesulitan), hampir semuanya menjawab "bertanya kepada kawan, membaca ulang dan browsing di internet". Untuk pertanyaan butir 5 (kenapa mengalami kesulitan) dan butir 6 (apasaran anda) jawabannya tertulis pada Tabel 2 di atas.

Banyak mahasiswa mengakui bahwa beberapa atau bahkan seluruh materisulit. Ada seorang mahasiswa mengatakan "mudah lupa". Hal tersebut sesuai dengan jawaban di angket bahwa ingatan atau kemampuanmereka dalam menerima materi "kurang".

Masih dari hasil angket, diketahui bahwa beberapa mahasiswa memiliki kekurangan pada materi prasyarat. Materi tersebut antara lain turunan, turunan parsial tingkat tinggi, harga mutlak dan integral rangkap.

Beberapa responden menyatakan "presentasi kelompok kurang membantu mahasiswa memahami" dan "diajar dosen saja”. Mereka menilai proses presentasi tidak efektif dan tidak efisien. Hal-hal tersebut berarti presentasi sebagai sarana bagi mahasiswa membangun pemahaman sendiri harus ditingkatkan kualitasnya.

Saran mereka agar perkuliahan "diajar dosen saja" menunjukkan bahwa mereka malas, kurang percaya diri, cemas atau bahkan malu ketika harus melakukan presentasi kelompok.

Saran mereka tentang perlunya disediakan satu buku wajib adalah positif dan dapat diterima. Ketika perkuliahan pertama dimulai, penulis menyarankan kepada mahasiswa untuk menggunakan beberapa buku bacaan. Namun keragaman bukudapatmengakibatkan keragaman persepsi, cara berfikir, simbol dan lain-lain yang ternyata menimbulkan kesulitan tersendiri bagi mahasiswa terutama yang terindikasi dyscalculia.

\section{Kesimpulan}

Berdasarkan uraian pada bagian sebelumnya, disimpulkan bahwa faktorfaktor psikis dominan penyebab terjadinya dyscalculia adalah: 1) ingatan/kemampuan $92,6 \%$ mahasiswa dalam menerima materi adalah 'kurang', 2) konsentrasi belajar $63 \%$ mahasiswa saat kuliah adalah 'kurang/sulit fokus', 3) rasa percaya diri $59,3 \%$ mahasiswa diikuti rasa 'cukup malu', dan 4) rasa percaya diri $59,3 \%$ mahasiswa diikuti rasa 'agak cemas' ketika menjalani tes, kuliah atau presentasi kelompok.

Disarankan pengampu matakuliah lainnya dapat melakukan penelitian serupa agar faktor-faktor psikis yang tersembunyi dalam diri dapat diungkap. Sebaiknya dilakukan wawancara lanjutan tentang alasan atas 
sarannya, karena "alasan mereka" boleh jadi merupakan penyebab awal terjadinya dyscalculia.

Penulis mengucapkan terimakasih kepada ketua program studi Pendidikan Matematika yang selalu memberikan dorongan. Penulis juga berterimakasih kepada tiga mahasiswa senior yang turut membantu pelaksanaan penelitian.

\section{Daftar Rujukan}

Arikunto, Suharsimi. 2006. Prosedur Penelitian Suatu Pendekatan Praktik. Jakarta: Bina Aksara.

Caryono, S dan Suhartono.2012. Analisis Faktor-faktor Penyebab Kesulitan Belajar Mat.Yogya: Prosiding Semnasmat FMIPA UNY.

Corey, Gerard. 2010. Teori dan Praktek Konseling dan Psikoterapi. Bandung: PT. Refika Aditama.

Davidson, J.E., dan Sternberg, R.J. 2003.The Psychology of Problem Sol-ving.Cambridge: Cambridge Uni-versity Press.

Fudyartanta. 2012. Psikologi Kepribadian. Yogya: Pustaka Pelajar.

Hallen, A. 2005.Bimbingan dan Konseling. Jakarta: Quantum Teaching.

Haryadi, D. 2007. Perilaku Bermasalah Remaja Muncul Lebih Dini. http://www.Duniaguru.com.Diaks es 29 September 2016.

Masrura, Sitti Inayah. 2013. Faktorfaktor Psikologis yang Mempengaruhi Kesadaran Metakognisi Mat.Jurnal Vol. 1 No. 1 Des. 2013. Makassar: UIN Alauddin.

Mason, J., Burton, L., Stacey, K. 2010. Thinking Mathematically, $2^{\text {nd }}$ Edition, Harlow: Prentice Hall.
Mulyasa, E. 2010.Menjadi Guru Profesional. Jakarta: PT. Rosdakarya.

Purwoto, A. 2007.Panduan Laboratorium Statistik Inferensial. Jakarta: PT. Gramedia.

Sardiman, A. M. 2006. Interaksi dan Motivasi Belajar Mengajar, Pedoman bagi Guru danCalon Guru. Jakarta: Raja Grafindo Persada.

Sholikah, A.U., Slamet. 2011. Analisis Kesulitan Mahasw.P. Mat. dlm Menyelesaikan Soal KPB di Univ. Muhd.Surakarta. Lap. Penelitian.

Soegiyono.2007. Metode Penelitian Pendidikan. Bandung: PT. Remaja Rosdakarya.

Soleh, M. 1999. Pokok-Pokok Pengajaran MatematikaSekolah.Jakarta: Depdikbud.

Sujarweni, V. Wiratna. 2014. SPSS untuk Penelitian. Yogyakarta: Penerbit Pustaka Baru Press.

Sufiyah, Siti. 2002. Analisis Kesalahan Penyelesaian Soal PDB Orde Satu pada Mahasiswa Semester V. Univ. Muhammdiah Purworejo.

Sumadji. 2010. Motivasi dan Cara Belajar Mahasiswa PMatematikaMalang: Laporan Penelitian.

Syah, Muhibbin. 2010. Psikologi Pendidikan dengan Pendekatan Baru. Bandung: Remaja Rosdakarya.

Widdiharto, Rachmadi. 2008. Diagnosis Kesulitan Belajar Matematika SMP dan Alternatif Remedinya, Yogyakarta: Pustaka Baru.

Yusuf, Munawir dkk.2003. Pendidikan Bagi Anak dengan Problema Belajar. Solo: PT Tiga Serangkai. 